\title{
Burnout in physicians
}

\author{
${ }^{1}$ YY Lee, ${ }^{2}$ ARL Medford, ${ }^{1}$ AS Halim \\ ${ }^{1}$ School of Medical Sciences, Universiti Sains Malaysia, Kelantan, Malaysia; ${ }^{2}$ North Bristol Lung Centre, Southmead Hospital, Bristol, UK
}

ABSTRACT Increasing numbers of doctors are experiencing burnout now more than ever before and the worrying part is that what we see is just the tip of the iceberg. Burnout, a state of mental exhaustion caused by the doctor's professional life, is characterised by emotional exhaustion, depersonalisation and a reduced sense of accomplishment or success. Burnout has been largely ignored or underrecognised previously. This paper provides a perspective on burnout among doctors, including an overview of symptoms, the scale of the problem, the implications and causes of burnout and, finally, a strategic framework to provide a basis for managing it. Most importantly, professional bodies are urged to start taking steps to help troubled doctors. Medical Colleges should provide essential assistance, support and guidance as well as ensuring fair management and promotion policies.

KEYWORDS burnout, emotional exhaustion, long working hours, management, physician

DECLARATION OF INTERESTS No conflict of interest declared.
Correspondence to Yeong Yeh Lee School of Medical Sciences Universiti Sains Malaysia 16150 Kubang Kerian Kelantan Malaysia e-mail justnleeyy@gmail.com

\section{INTRODUCTION}

Doctors attract more internet links with 'burnout' than any other profession. Furthermore, doctors are vocalising their concerns over this escalating problem. Increasingly, many physicians experience variable episodes of burnout throughout their career, but few are able to cope without consequences. Recent data from a US national study paint a rather bleak picture of burnout among our early career colleagues especially residents and fellows during their training periods; this group is also more likely to report depression and high levels of fatigue.' It must be acknowledged that our profession has changed significantly in recent times. These changes vary across the globe, but include greater competition for training fellowships, longer working hours, more work-family conflicts, and tougher working conditions in our highly hierarchical organisations.

Coined in the 1970s by psychologist Herbert Freudenberger, burnout is 'a state of mental exhaustion caused by one's professional life' that consists of three salient features: emotional exhaustion, depersonalisation and a reduced sense of accomplishment or success (Table I). ${ }^{2}$ Emotional exhaustion is the earliest and most important sign and many consider reduced accomplishment as a complication of exhaustion rather than a cause. Several scales are available to identify and measure burnout; these include the Maslach Burnout Inventory-General Survey, ${ }^{3}$ the Oldenburg Burnout Inventory ${ }^{4}$ and the Copenhagen Burnout Inventory. ${ }^{5}$ Table 2 describes their advantages and disadvantages. The British Medical Association offers a confidential online questionnaire to help screen their doctors and

TABLE I Three features of burnout
\begin{tabular}{|l|l|}
\hline Features & Explanation \\
\hline Emotional exhaustion & $\begin{array}{l}\text { Emotional depletion from being } \\
\text { overworked }\end{array}$ \\
\hline Depersonalisation & $\begin{array}{l}\text { A sense of being unfeeling towards } \\
\text { patients or peers; often negative, } \\
\text { callous and detached responses }\end{array}$ \\
\hline Professional efficacy & $\begin{array}{l}\text { A reduced sense of competence or } \\
\text { achievement in one's work; this is a } \\
\text { domain specific to the human } \\
\text { services industry }\end{array}$ \\
\hline
\end{tabular}

provides links for further information, ${ }^{6}$ a resource that other medical societies should be encouraged to adopt.

\section{A BIGGER PROBLEM BELOW THE TIP OF THE ICEBERG}

How big is this problem? In a study from the US that involved 7288 physicians, $45.8 \%$ experienced at least one symptom of burnout, with the highest rates reported among the frontline physicians working in family medicine, general internal medicine and emergency medicine. ${ }^{7}$ Compared to the general US population, physicians work for longer hours and are more dissatisfied with their work-life balance, especially among female physicians. Similar figures are captured by a survey from Medscape. ${ }^{8}$ American surgeons are as burnt out as physicians, with a third of them screening positive for depression. ${ }^{9}$ Figure I shows percentages of burnout 
TABLE 2 Advantages and disadvantages of three of the main burnout scales

\begin{tabular}{|c|c|c|}
\hline Common Burnout Scales & Advantages & Disadvantages \\
\hline $\begin{array}{l}\text { Maslach Burnout Inventory-General } \\
\text { Survey }\end{array}$ & $\begin{array}{l}\text { - More widely used/known } \\
\text { - Three dimensions } \\
\text { - Mainly human services but devised } \\
\text { for general use }\end{array}$ & $\begin{array}{l}\text { - } \quad \text { All items negatively phrased } \\
\text { - } \begin{array}{l}\text { More emphasis on emotional aspect of } \\
\text { exhaustion }\end{array} \\
\begin{array}{l}\text { Copyrighted/distributed by a } \\
\text { commercial publisher }\end{array} \\
\end{array}$ \\
\hline Oldenburg Burnout Inventory & $\begin{array}{l}\text { Items a mixture of positive and } \\
\text { negative phrases } \\
\text { - Covers physical and cognitive } \\
\text { aspects of exhaustion } \\
\text { - } \quad \text { Free to use }\end{array}$ & $\begin{array}{l}\text { Two dimensions (professional efficacy } \\
\text { is not included although many } \\
\text { considered this a weaker construct) }\end{array}$ \\
\hline Copenhagen Burnout Inventory & $\begin{array}{l}\text { Besides personal aspect of } \\
\text { exhaustion, work and client } \\
\text { aspects of burnout are also } \\
\text { assessed } \\
\text { - Free to use }\end{array}$ & - $\quad$ Single dimension (only exhaustion) \\
\hline
\end{tabular}

reported across different specialties in the US based on a study by Shanafelt et al. ${ }^{7}$ Data are similarly discouraging for training residents (27-75\%, depending on specialty) and medical academics. ${ }^{10,11}$ Data are lacking in Asia, but the reported burnout rate among physicians in Malaysia was no different, with a study indicating a rate of $36.6 \%$ among medical residents. ${ }^{2}$ However, many reported surveys have only had a response rate of less than one third and this suggests a bigger problem below the tip of the iceberg.

The greatest issue with burnout is its consequences for doctors, patients and society. Burnout will very often result in someone leaving the profession and this can cause potential unemployment, financial loss and more family conflict. Physicians are more likely to abuse substances, become offensive or violent at work, suffer from depression and have higher suicide rates. ${ }^{13}$ Medical errors are also more likely in those suffering from burnout ${ }^{14}$ and these may result in malpractice suits that can devastate most physicians and magnify the problems.

\section{WHAT CAUSES BURNOUT?}

Excessive workload and loss of control in one's profession are cited as the top reasons for burnout among physicians. ${ }^{8}$ Likewise, among surgeons, a primary contributing factor for burnout is long working hours, with only a third of surgeons feeling their work schedule had left enough time for personal or family life. ${ }^{9}$ Workfamily conflicts are also more common if surgeons are married to another physician or surgeon. Clearly these reasons imply that a primary root of the problem lies with organisations and care delivery systems rather than the individuals. Furthermore, workplace politics can be associated with a higher risk of burnout, depression and coronary artery disease. ${ }^{15}$ Adequate staffing, good

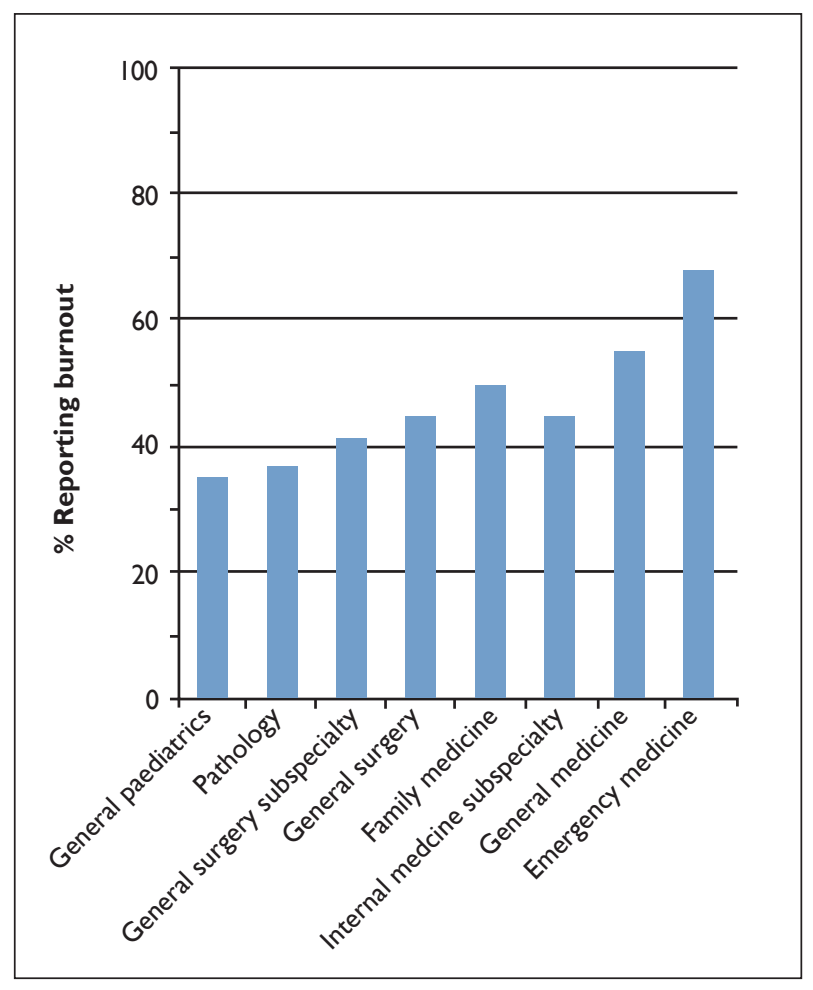

FIGURE I Percentage of burnout across different medical specialties in the US

leadership and support were found to reduce the risk of burnout, highlighting the importance of fair hospital management, policy and practice. ${ }^{16}$

Causes of burnout are not always organisational in nature; a proportion are due to the mishandling of stress related to the profession or at work. ${ }^{17}$ This is especially evident among vulnerable physicians with traits including idealism, perfectionism and a great sense of responsibility. ${ }^{18}$ Early career physicians (i.e. $\leq 5$ years in practice) who 
have these personality traits are at a greater risk, particularly during the first few years immediately after completion of their fellowship. An early presence in academic and private settings and being involved in interventional procedures can be stressful to an early career physician. ${ }^{19}$ In addition, certain patient factors may also contribute to burnout; these include unrealistic expectations, declining patient health and aggression from patients. Prolonged patient contact and development of family-like relationships may also result in emotional detachment and burnout.

\section{A CONCEPTUAL MODEL: THE 'TRAFFIC-LIGHT' APPROACH}

At the moment, there is no specialised help for physicians seeking assistance for their burnout symptoms. There is limited information and there are few self-help guides available, and most medical societies have no such provision. Most worrying is that cases often go unrecognised as many professionals are reluctant to acknowledge that they have problems. ${ }^{20}$ Professionals with severe burnout symptoms are not required to stop their practice by law, but these individuals should be identified, given advice and allowed temporary leave if necessary before medical errors can occur. Until medical professional bodies recognise the size of the burnout problem and start taking action physicians can only help themselves.

There are several good reviews on interventions and coping strategies. ${ }^{21-23} \mathrm{We}$ summarise these strategies as a conceptual 'traffic-light' model. If you are a doctor at a crossroads, with emotional exhaustion from work, think about the colours of traffic-lights (Figure 2). First, stop (red) and evaluate if you are suffering from burnout. Doctors frequently fail to recognise burnout, especially when there is an absence of psychological distress. Your colleagues, patients or family members may however notice and let you know. Second, pause (yellow) and

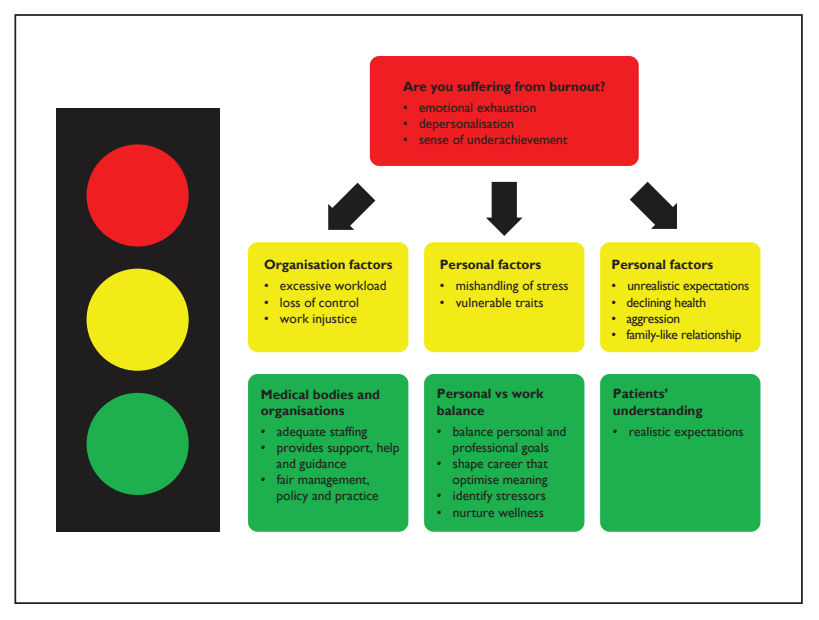

FIGURE 2 Traffic light model think why you are suffering from burnout and what impact this might have on your life. Causes of your burnout may be due to three factors: organisational, personal or related to patients. Psychological disturbance and dysfunctional social relationships from burnout will have a great impact on you and these should be recognised early on. Third, initiate (green) coping strategies before your life starts a downward spiral. These strategies target the three factors that cause burnout including support from medical bodies or organisations, balancing personal and work life, and obtaining an understanding from patients of your problems. Table 3 provides a further explanation of the traffic-light model and is available with the online version of this paper.

\section{CONCLUSIONS}

Further studies are required to evaluate the magnitude, of and interventions for burnout in our profession. Burnout symptoms do not make us bad doctors, but acknowledging burnout and seeking help will enable us to become better and more satisfied individuals. We hope our patients will understand that doctors are humans just as they are. But most importantly, it is time for our organisations to help those suffering from burnout to move beyond the 'traffic-lights' at their crossroads and provide the necessary assistance, support and guidance as well as advocate fair management and promotion policies. 


\section{REFERENCES}

I Dyrbye LN, West CP, Satele D et al. Burnout among U.S. medical students, residents, and early career physicians relative to the general U.S. population. Acad Med 20I4; 89: 443-5I. http://dx.doi. org/I0.1097/ACM.0000000000000 I 34

2 Freudenberger HJ, Richelson G. Burn Out: The High Cost of High Achievement. New York: Bantam Books; 1980.

3 Maslach C, Schaufeli WB, Leiter MP. Job burnout. Annu Rev Psychol 200I; 52: 397-422.

4 Demerouti E, Bakker AB.The Oldenburg Burnout Inventory:A good alternative to measure burnout and engagement. In: Halbesleben J, editor. Handbook of Stress and Burnout in Health Care. New York: Nova Science Publishers; 2008. p.65-78.

5 Kristensen TS, Borritz M,Villadsen E et al.The Copenhagen Burnout Inventory: A new tool for the assessment of burnout. Work \& Stress 2005; 19: 192-207. http://dx.doi.org/ I 0.1080/02678370500297720

6 British Medical Association. Doctors for Doctors - Burnout Questionnaire. https://web2.bma.org.uk/drs4drsburn.nsf/quest?OpenForm (accessed I I/4/20I5).

7 Shanafelt TD, Boone S, Tan L et al. Burnout and satisfaction with work-life balance among US physicians relative to the general US population. Arch Intern Med 20 I2; I72: I377-85.

8 Peckham C. Physician lifestyle - Linking to Burnout:A Medscape Survey. Medscape; 20I3. http://www.medscape.com/features/slideshow/ lifestyle/20I3/public (accessed I0/4/20I5).

9 Shanafelt TD, Balch CM, Bechamps GJ et al. Burnout and career satisfaction among American surgeons. Ann Surg 2009; 250:463-7I. http://dx.doi.org/I0.1097/SLA.0b0 I 3e3 I8Iac4dfd

10 Ishak WW, Lederer S, Mandili C et al. Burnout during residency training: a literature review.J Grad Med Educ 2009; I: 236-42. http:// dx.doi.org/I0.4300/JGME-D-09-00054.I

II Tijdink JK, Vergouwen ACM, Smulders YM. Publication pressure and burn out among Dutch medical professors: a nationwide survey. PLoS One 2013; 8:e7338I. http://dx.doi.org/I0.137//journal. pone.007338I

12 Al-Dubai SAR, Ganasegeran K, Perianayagam W et al. Emotional burnout, perceived sources of job stress, professional fulfillment, and engagement among medical residents in Malaysia. Scientific World Journal 2013; 20I3: 137620. http://dx.doi. org/10.1155/2013/137620
I3 Lee RT, Seo B, Hladkyj S et al. Correlates of physician burnout across regions and specialties: a meta-analysis. Hum Resour Health 20I3; I I: 48. http://dx.doi.org/ I 0. I I86/I478-449 I-I I-48

14 West CP, Tan AD, Habermann TM et al. Association of resident fatigue and distress with perceived medical errors. JAMA 2009; 302 1294-300. http://dx.doi.org/I0.100 I/jama.2009.I389

I5 Grynderup MB, Mors O, Hansen ÅM et al.Work-unit measures of organisational justice and risk of depression - a 2-year cohort study. Occup Environ Med 20 I 3; 70:380-5. http://dx.doi.org/ I 0.I I 36 / oemed-20I2-I0I000

16 Shanafelt TD, Gorringe G, Menaker R et al. Impact of organizational leadership on physician burnout and satisfaction. Mayo Clin Proc 20I5; 90: 432-40. http://dx.doi.org/I0.10I6/j.mayocp.20I5.0I.0I2

17 McManus IC, Winder BC, Gordon D. The causal links between stress and burnout in a longitudinal study of UK doctors. Lancet 2002; 359: 2089-90.

18 Christensen JF, Levinson W, Dunn PM. The heart of darkness: the impact of perceived mistakes on physicians.J Gen Intern Med 1992; 7: 424-3I.

19 Keswani RN, Taft TH, Coté GA et al. Increased levels of stress and burnout are related to decreased physician experience and to interventional gastroenterology career choice: findings from a US survey of endoscopists. Am J Gastroenterol 20II; 106: 1734-40. http://dx.doi.org/I0.1038/ajg.20II.148

20 Devi S. Doctors in distress. Lancet 20 I I; 377: 454-5. http://dx.doi. org/I0.I0I6/S0I40-6736(II)60I45-I

21 Shanafelt T.A career in surgical oncology: finding meaning, balance, and personal satisfaction. Ann Surg Oncol 2008; 15: 400-6.

22 Surawicz CM. J. Edward Berk distinguished lecture: avoiding burnout: finding balance between work and everything else. Am J Gastroenterol 20I4; 109: 5II-4. http://dx.doi.org/I0.1038/ ajg.2014.44

23 Montgomery A.The inevitability of physician burnout : Implications for interventions. Burnout Research 20I4; I: 50-6. http://dx.doi. org/I0.1016/j.burn.2014.04.002 